\title{
COMPARATIVE STUDY OF FUZZY LOGIC AND ANN FOR SHORT TERM LOAD FORECASTING
}

\author{
Patel Parth Manoj ${ }^{1}$, Ashish Pravinchandra $\mathrm{Shah}^{2}$ \\ ${ }^{I}$ M.E. Student, Electrical Engineering Department, Parul Institute of Engineering and Technology, Limda Waghodia, \\ Vadodara, India \\ ${ }^{2}$ Assistant Professor, Electrical Engineering Department, Parul Institute of Engineering and Technology, Limda \\ Waghodia, Vadodara, India
}

\begin{abstract}
Load forecasting is an important component for power system energy management system. Precise load forecasting helps the electric utility to make unit commitment decisions, reduce spinning reserve capacity and schedule device maintenance plan properly and it also reduces the generation cost and increases reliability of power systems. In this work, a fuzzy logic as well as artificial neural network approach for short term load forecasting is attempted. Time, temperature and similar previous day load are used as the independent variables for short term load forecasting. Based on the time, temperature and similar previous day load, fuzzy rule base are prepared using mamdani implication, which are eventually used for the short term load forecasting. Similarly, monthly load data along with forecasted temperature are used to train the neural network. MATLAB SIMULINK software is used here in this work. For the short term load forecasting, load data from the specific area load dispatch center is considered.
\end{abstract}

Keywords: Load forecasting, short term load forecasting, Fuzzy logic, Fuzzy inference system, artificial neural network.

\section{INTRODUCTION}

Short term load forecasting is basically is a load predicting system with a leading time of one hour to seven days, which is necessary for adequate scheduling and operation of power systems. For proper and profitable management in electrical utilities, short-term load forecasting has lot of importance [1].

High forecasting accuracy as well as speed is the two most vital requirements of short-term load forecasting and it is of utmost importance to analyze the load characteristics and identify the main factors affecting the load. In electricity markets, the traditional load affecting factors such as season, day type and weather, electricity price have a complicated relationship with system load [1].

\section{ARTIFICIAL INTELLEGENCE METHODS OF}

\section{SHORT TERM LOAD FORECASTING}

\subsection{Fuzzy Logic}

Fuzzy logic based on the Boolean logic which is used for digital circuit design and operation. In Boolean logic, the input may be the truth value in the form of " 0 " and " 1 ". In case of fuzzy logic, the input is related to the comparison based on qualities. For example, we can say that a transformer load may be "low" and "high". Fuzzy logic allows us to deduce outputs form inputs logically. In this sense, the fuzzy logic gives facility to map between inputs and outputs like curve fitting.
The advantage of fuzzy logic is that there is no need of mathematical models for mapping between inputs and outputs and also there is no need of precise or even noise free inputs. Based on the general rules, properly designed fuzzy logic systems are very strong for the electrical load forecasting. There are many situations where we require the precise outputs. After the whole processing is done using the fuzzy logic, the "defuzzification" is done to get the crisp outputs. We know that power system load is influenced by many load factors such weather, economic, social activities, and day type. By the analysis of historical load data it is not easy to make the accurate forecast. The use of these intelligent methods like fuzzy logic and expert systems provide advantage on other conventional methods. The numerical aspects and uncertainties are suitable for the fuzzy methodology.

\subsection{Artificial Neural Network}

Artificial Neural Network (ANN) based on the working of our brain. Brain basically learns from the experience. This biological inspired method is thought to be the major development in the computational industry. In a neural network, the basic element which does all the process is the neuron. These neurons get input from some source, combine them, perform all necessary operations and put the final results on the output.

Forecasting is based on the pattern observed from the past event and estimates the values for the future. ANN is suitable 
for load forecasting for two reasons. First, it has been proved that ANN is able to approximate numerically any continuous function to be desired accuracy. In this case the ANN is seen as multivariate, nonlinear and nonparametric methods. Secondly, ANNs are date-driven methods, in the sense that it is not necessary for the researcher to use tentative models and then estimate their parameters. ANNs are able to automatically map the relationship between input and output; they learn this relationship and store this learning into their parameters. [1]

\section{FUZZY LOGIC METHODOLOGY FOR SHORT TERM LOAD FORECASTING}

\subsection{Fuzzification}

Fuzzification is the process of converting crisp numerical values into the degrees of membership related to the corresponding fuzzy sets. A MF will accept as its argument a crisp value and return the degree to which that value belongs to the fuzzy set the MF represents. In order to express the fuzziness of data, this paper makes an arrangement of fuzzy subsets for different inputs and outputs in complete universe of discourse as membership functions. The relationship between several inputs and output may be nonlinear but linear membership functions have been used for simplicity. A rectangular membership function is used for the inputs as well as the output.

The two inputs taken for STLF are Time and Temperature. As shown in figure (Fig -1) time is divided into seven triangular membership functions which are as follows:

- Mid Night (MID-NIG)

- Dawn (DAWN)

- $\quad$ Morning (MORN)

- $\quad$ Noon (NOON)

- Evening (EVE)

- Dusk (DUSK)

- $\quad$ Night (NIGHT)

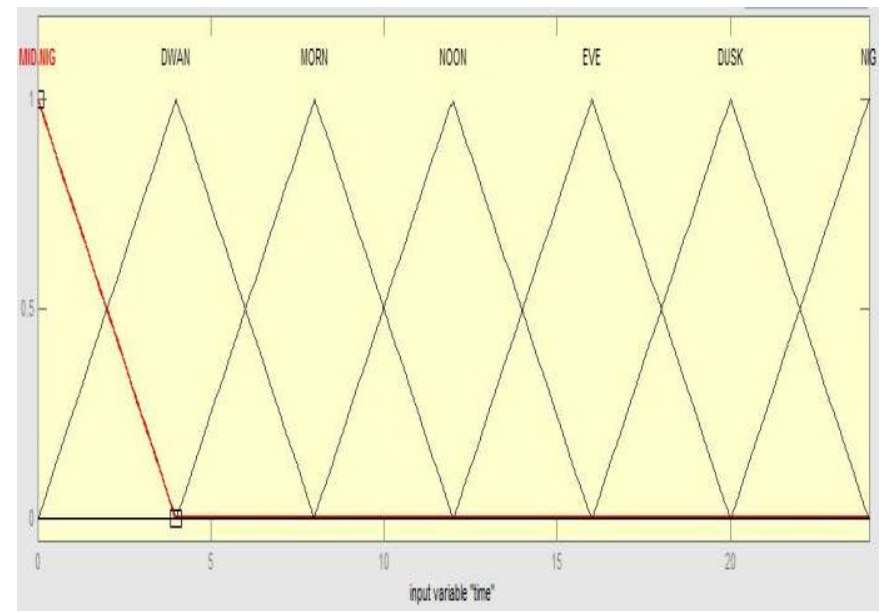

Fig -1: Triangular membership function for time
Figure (Fig -2) shows temperature divided into seven triangular membership functions which are as follows:

- Very Very Low (VVL)

- Very Low (VL)

- $\quad$ Low (L)

- $\quad \operatorname{Normal}(\mathrm{N})$

- $\operatorname{High}(\mathrm{H})$

- $\quad$ Very High (VH)

- Very Very High (VVH)

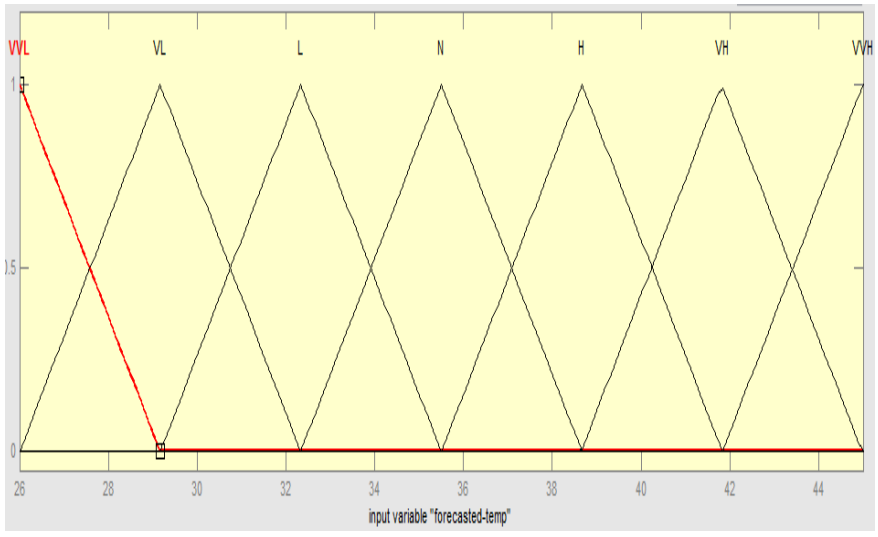

Fig -2: Triangular membership function for forecasted temperature

Figure (Fig -3) shows similar pervious day load divided into seventeen triangular membership functions which are from L8 to $\mathrm{H} 8$.

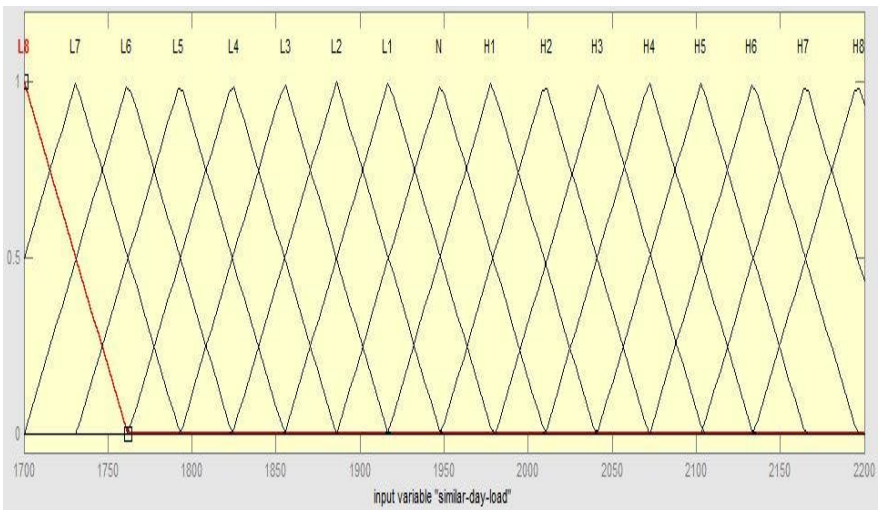

Fig -3: Triangular membership function for similar pervious day load

Figure (Fig -4) shows forecasted load (output) divided into seventeen triangular membership functions which are from L8 to $\mathrm{H} 8$. 


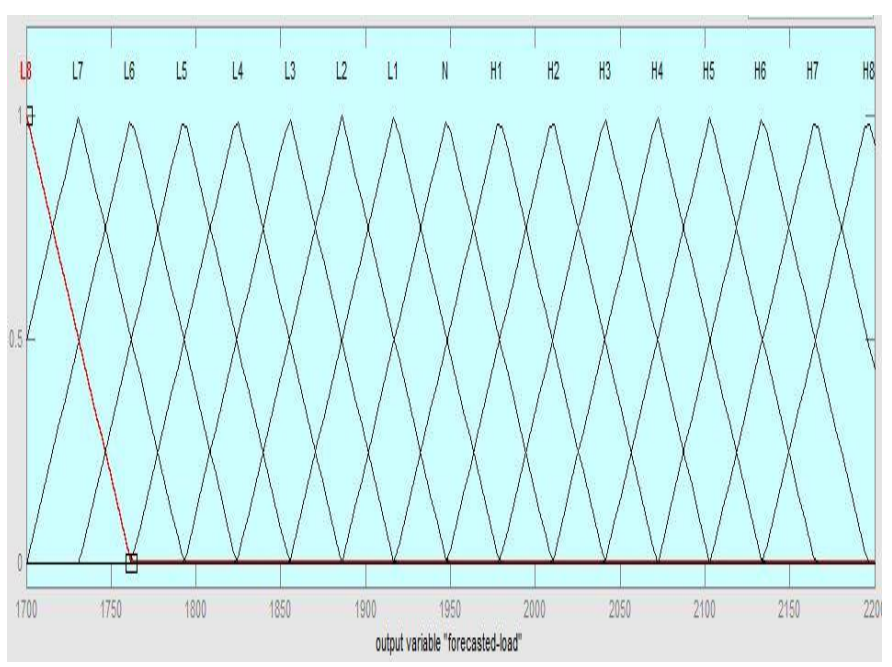

Fig -4: Triangular membership function for forecasted load

\subsection{Fuzzy Rule Base}

This part is the heart of the fuzzy system. The heuristic knowledge of the forecasted is stored in terms of "IF-THEN" rules. It sends information to fuzzy inference system, which evaluates the gained information to get the load forecasted output. Some of the rules are as follows:

- If (time is MID.NIG) and (forecasted-Temperature is VL) and (similar-day-load is H1) then (forecastedload is H1) (1)

- If (time is MID.NIG) and (forecasted-Temperature is VL) and (similar-day-load is H2) then (forecastedload is H2) (1)

- If (time is MID.NIG) and (forecasted-Temperature is $\mathrm{VL}$ ) and (similar-day-load is H3) then (forecastedload is H3) (1)

- If (time is MID.NIG) and (forecasted-Temperature is $\mathrm{VL}$ ) and (similar-day-load is H4) then (forecastedload is H4) (1)

- If (time is MID.NIG) and (forecasted-Temperature is L) and (similar-day-load is H1) then (forecasted-load is H1) (1)

Similarly, 381 fuzzy rules are prepared based on the data obtained from ALDC, Jambuva, Vadodara.

\subsection{Simulation Work}

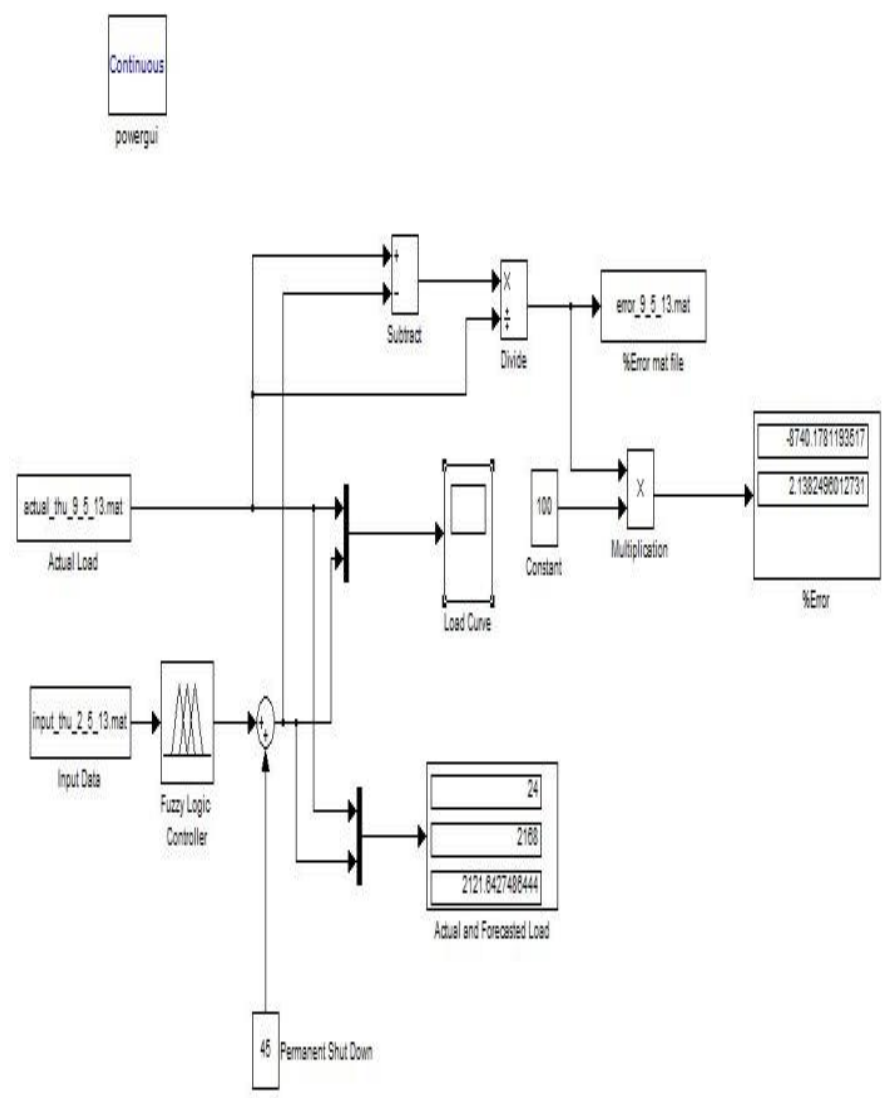

Fig -5: Simulation of short term load forecasting using fuzzy logic in MATLAB

Figure (Fig -5) shows the simulation of fuzzy logic methodology short term load forecasting. MATLAB is used for the simulation purpose. As shown in the figure (Fig -5) the input data's as well as actual load occurred are loaded. The input data are given to fuzzy logic controller block. In fuzzy logic controller block ".fis" of fuzzy inference system is loaded. Based on the rules prepared the fuzzy logic controller give forecasted output corresponding to the input data. Then the permanent shut down block is added. If a substation is in working state for pervious similar day and there is a permanent shutdown for the forecasted day, then the megawatts supplied by the substation need to be subtracted from the forecasted load and vice versa. Thus, final forecast of the day is obtained. Also, the error is calculated along with the forecasting as shown in figure (Fig -5).

Table 1 and Table 2 show the actual load, fuzzy forecasted load and also the percentage error in the fuzzy forecasted load. The load forecast is done for the day 8th May 2013 and 9th May 2013 respectively. 
Table -1: Fuzzy load forecast of $8^{\text {th }}$ May 2013

\begin{tabular}{|c|c|c|c|c|c|}
\hline $\begin{array}{l}\text { Time } \\
\text { (Hrs.) }\end{array}$ & $\begin{array}{l}\text { Forecasted } \\
\text { Temp. }\left({ }^{\circ} \mathrm{C}\right)\end{array}$ & $\begin{array}{c}\text { Pervious } \\
\text { Similar } \\
\text { Day } \\
\text { Load } \\
(\mathrm{MW})\end{array}$ & $\begin{array}{c}\text { Actual } \\
\text { Load } \\
(\mathrm{MW})\end{array}$ & $\begin{array}{c}\text { Fuzzy } \\
\text { Forecast } \\
\text { ed Load } \\
(\mathrm{MW})\end{array}$ & $\%$ Error \\
\hline 1 & 32 & 2058 & 2035 & 2050.12 & -0.714 \\
\hline 2 & 31 & 2013 & 2006 & 2012.73 & -0.316 \\
\hline 3 & 30 & 1983 & 1989 & 1982.40 & 0.329 \\
\hline 4 & 30 & 1963 & 1938 & 1963.11 & -1.282 \\
\hline 5 & 30 & 1933 & 1935 & 1932.60 & 0.136 \\
\hline 6 & 29 & 1959 & 1942 & 1946.50 & -0.252 \\
\hline 7 & 29 & 1902 & 1900 & 1901.86 & -0.098 \\
\hline 8 & 31 & 1854 & 1888 & 1855.38 & 1.754 \\
\hline 9 & 32 & 2018 & 2013 & 2018.24 & -0.282 \\
\hline 10 & 35 & 2077 & 2050 & 2075.22 & -1.238 \\
\hline 11 & 37 & 2104 & 2094 & 2088.68 & 0.277 \\
\hline 12 & 39 & 2131 & 2076 & 2106.62 & -1.476 \\
\hline 13 & 41 & 2062 & 2002 & 2039.94 & -1.884 \\
\hline 14 & 42 & 2079 & 2050 & 2061.00 & -0.513 \\
\hline 15 & 43 & 2128 & 2091 & 2111.56 & -0.960 \\
\hline 16 & 44 & 2060 & 2076 & 2043.73 & 1.596 \\
\hline 17 & 43 & 2005 & 1959 & 1983.10 & -1.204 \\
\hline 18 & 42 & 1980 & 1929 & 1964.19 & -1.779 \\
\hline 19 & 39 & 1914 & 1930 & 1915.87 & 0.745 \\
\hline 20 & 37 & 2014 & 2019 & 2027.16 & -0.402 \\
\hline 21 & 37 & 2021 & 2038.8 & 2029.61 & 0.456 \\
\hline 22 & 36 & 1967 & 1975 & 1999.26 & -1.213 \\
\hline 23 & 34 & 2006 & 2020 & 2016.22 & 0.187 \\
\hline 24 & 33 & 2066 & 2100 & 2086.33 & 0.655 \\
\hline
\end{tabular}

Table -2: Fuzzy load forecast of $9^{\text {th }}$ May 2013

\begin{tabular}{|c|c|c|c|c|c|}
\hline $\begin{array}{l}\text { Time } \\
\text { (Hrs.) }\end{array}$ & $\begin{array}{l}\text { Forecasted } \\
\text { Temp. }\left({ }^{\circ} \mathrm{C}\right)\end{array}$ & $\begin{array}{l}\text { Pervious } \\
\text { Similar } \\
\text { Day Load } \\
\text { (MW) }\end{array}$ & $\begin{array}{l}\text { Actual } \\
\text { Load } \\
(\mathrm{MW})\end{array}$ & $\begin{array}{l}\text { Fuzzy } \\
\text { Forecast } \\
\text { ed Load } \\
(\mathrm{MW})\end{array}$ & $\%$ Error \\
\hline 1 & 31 & 2015 & 2056 & 2060.68 & -0.2411 \\
\hline 2 & 30 & 1988 & 2020 & 2033.06 & -0.6512 \\
\hline 3 & 29 & 1947 & 1981 & 1991.68 & -0.5396 \\
\hline 4 & 28 & 1923 & 1970 & 1968.52 & 0.0563 \\
\hline 5 & 27 & 1880 & 1945 & 1925.43 & 1.01495 \\
\hline 6 & 26 & 1942 & 1959 & 1986.72 & -1.4300 \\
\hline 7 & 27 & 1885 & 1928 & 1929.83 & -0.0797 \\
\hline 8 & 28 & 1838 & 1880 & 1883.22 & -0.1819 \\
\hline 9 & 31 & 2034 & 2077 & 2077.99 & -0.0295 \\
\hline 10 & 34 & 2113 & 2159 & 2141.08 & 0.8151 \\
\hline 11 & 36 & 2136 & 2145 & 2170.10 & -1.1640 \\
\hline 12 & 39 & 2133 & 2165 & 2154.37 & 0.4680 \\
\hline 13 & 40 & 2036 & 2088 & 2065.40 & 1.0629 \\
\hline 14 & 42 & 2105 & 2141 & 2118.66 & 1.0650 \\
\hline 15 & 43 & 2122 & 2187 & 2144.67 & 1.9187 \\
\hline 16 & 43 & 2090 & 2160 & 2125.87 & 1.5781 \\
\hline 17 & 43 & 2030 & 2062 & 2043.28 & 0.9307 \\
\hline 18 & 42 & 1971 & 2043 & 2005.62 & 1.8454 \\
\hline 19 & 39 & 1957 & 2010 & 2002.95 & 0.3383 \\
\hline 20 & 36 & 2014 & 2105 & 2075.03 & 1.4449 \\
\hline 21 & 34 & 2025 & 2072 & 2094.16 & -1.0611 \\
\hline 22 & 33 & 1989 & 2102 & 2045.00 & 2.6956 \\
\hline 23 & 33 & 2024 & 2093 & 2085.89 & 0.3560 \\
\hline 24 & 31 & 2050 & 2168 & 2121.64 & 2.1436 \\
\hline
\end{tabular}




\section{ANN BASED METHODOLOGY FOR SHORT TERM LOAD FORECASTING}

The basic structure of artificial neural network is show in figure (Fig -6). As seen from the figure (Fig -6), there are three layers: input layer, hidden layer and output layer. There are three inputs used for short term load forecasting: time, forecasted temperature and previous similar day load. The number of neurons used in hidden layer is 200. The output layer gives one output i.e. forecasted load.

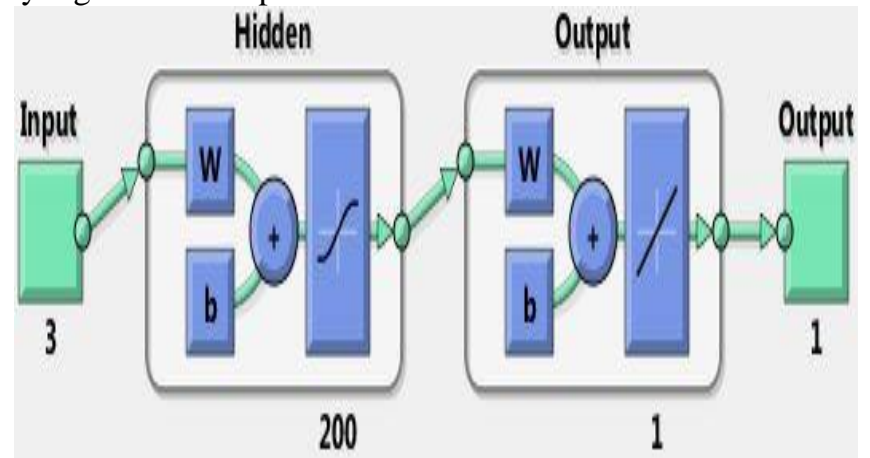

Fig -6: Basic structure of ANN for short term load forecasting.

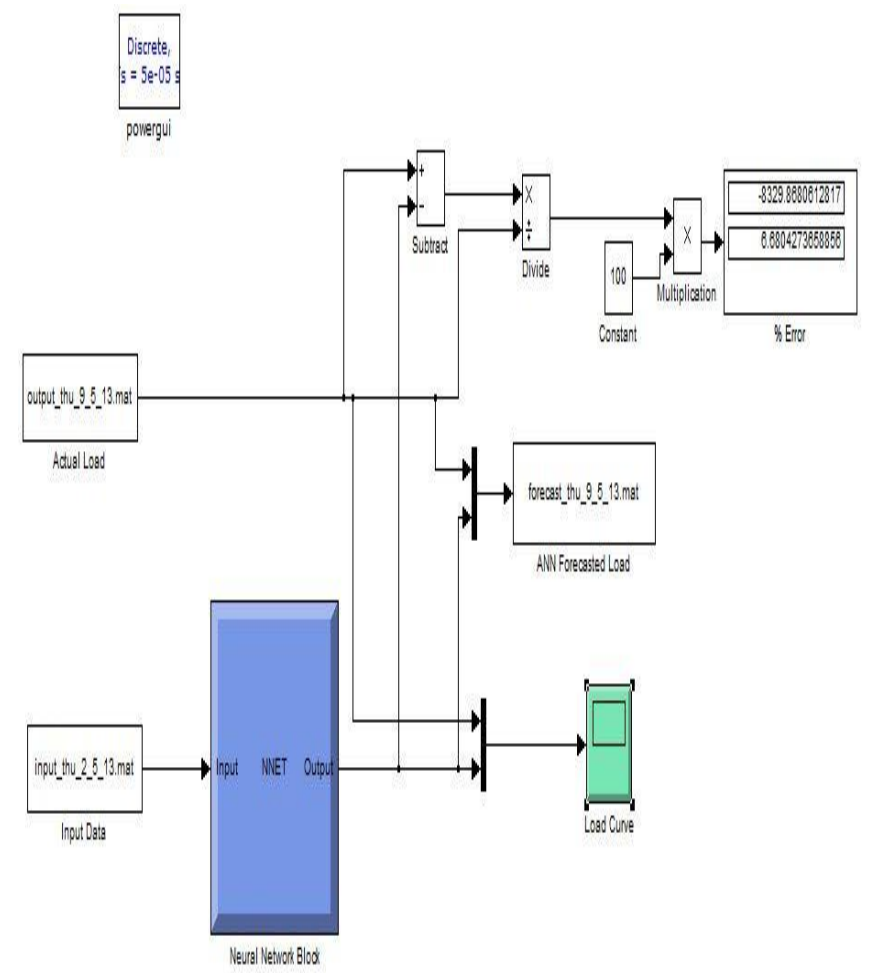

Fig -7: Simulation of short term load forecasting using ANN in MATLAB.

Now, for the training of NN, 15 days data are used. The data consists of time for which forecast is to be done, forecasted temperature for that day and previous similar day load. After the training of neural network, MATLAB simulation is prepared as shown in figure (Fig -7). The input data are loaded and is given to neural network block, which is trained using 15 days data of May 2013. The forecasted load using ANN can be seen in the scope. The error is also generated and displayed on the display.

Table 3 and Table 4 show the actual load, ANN forecasted load and also the percentage error in the ANN forecasted load. The load forecast is done for the day 8th May 2013 and 9th May 2013 respectively.

Table -3: ANN Load Forecast of $8^{\text {th }}$ May 2013

\begin{tabular}{|c|c|c|c|c|c|}
\hline $\begin{array}{l}\text { Time } \\
\text { (Hrs.) }\end{array}$ & $\begin{array}{l}\text { Forecasted } \\
\text { Temp. }\left({ }^{\circ} \mathrm{C}\right)\end{array}$ & $\begin{array}{c}\text { Pervious } \\
\text { Similar } \\
\text { Day } \\
\text { Load } \\
(\mathrm{MW})\end{array}$ & $\begin{array}{l}\text { Actual } \\
\text { Load } \\
(\mathrm{MW})\end{array}$ & $\begin{array}{c}\text { ANN } \\
\text { Forecast } \\
\text { ed Load } \\
(\mathrm{MW})\end{array}$ & $\%$ Error \\
\hline 1 & 32 & 2058 & 2035 & 1989.55 & 2.2564 \\
\hline 2 & 31 & 2013 & 2006 & 1986.25 & 1.0025 \\
\hline 3 & 30 & 1983 & 1989 & 1973.29 & 0.7866 \\
\hline 4 & 30 & 1963 & 1938 & 1946.63 & -0.448 \\
\hline 5 & 30 & 1933 & 1935 & 1909.48 & 1.3307 \\
\hline 6 & 29 & 1959 & 1942 & 1912.53 & 1.4961 \\
\hline 7 & 29 & 1902 & 1900 & 1890.82 & 0.4818 \\
\hline 8 & 31 & 1854 & 1888 & 1882.93 & 0.2653 \\
\hline 9 & 32 & 2018 & 2013 & 2015.56 & -0.150 \\
\hline 10 & 35 & 2077 & 2050 & 2091.12 & -2.029 \\
\hline 11 & 37 & 2104 & 2094 & 2110.80 & -0.778 \\
\hline 12 & 39 & 2131 & 2076 & 2120.25 & -2.155 \\
\hline 13 & 41 & 2062 & 2002 & 2076.71 & -3.758 \\
\hline 14 & 42 & 2079 & 2050 & 2079.48 & -1.417 \\
\hline 15 & 43 & 2128 & 2091 & 2105.97 & -0.702 \\
\hline 16 & 44 & 2060 & 2076 & 2048.30 & 1.3509 \\
\hline 17 & 43 & 2005 & 1959 & 1996.55 & -1.905 \\
\hline 18 & 42 & 1980 & 1929 & 1981.43 & -2.704 \\
\hline 19 & 39 & 1914 & 1930 & 1967.64 & -1.942 \\
\hline 20 & 37 & 2014 & 2019 & 2005.89 & 0.6490 \\
\hline 21 & 37 & 2021 & 2038 & 2004.50 & 1.6859 \\
\hline 22 & 36 & 1967 & 1975 & 1990.80 & -0.800 \\
\hline 23 & 34 & 2006 & 2020 & 2008.22 & 0.5827 \\
\hline 24 & 33 & 2066 & 2100 & 2020.39 & 3.7906 \\
\hline
\end{tabular}


Table 4: ANN Load Forecast of $9^{\text {th }}$ May 2013

\begin{tabular}{|c|c|c|c|c|c|}
\hline $\begin{array}{l}\text { Time } \\
\text { (Hrs.) }\end{array}$ & $\begin{array}{l}\text { Forecasted } \\
\text { Temp. }\left({ }^{\circ} \mathrm{C}\right)\end{array}$ & $\begin{array}{c}\text { Pervious } \\
\text { Similar } \\
\text { Day } \\
\text { Load } \\
(\mathrm{MW})\end{array}$ & $\begin{array}{l}\text { Actual } \\
\text { Load } \\
(\mathrm{MW})\end{array}$ & $\begin{array}{l}\text { ANN } \\
\text { Forecast } \\
\text { ed Load } \\
\text { (MW) }\end{array}$ & $\%$ Error \\
\hline 1 & 31 & 2015 & 2056 & 1987.43 & 3.3223 \\
\hline 2 & 30 & 1988 & 2020 & 1980.90 & 1.9309 \\
\hline 3 & 29 & 1947 & 1981 & 1946.05 & 1.7632 \\
\hline 4 & 28 & 1923 & 1970 & 1913.41 & 2.8540 \\
\hline 5 & 27 & 1880 & 1945 & 1906.98 & 1.9637 \\
\hline 6 & 26 & 1942 & 1959 & 1927.51 & 1.5929 \\
\hline 7 & 27 & 1885 & 1928 & 1912.85 & 0.8010 \\
\hline 8 & 28 & 1838 & 1880 & 1901.02 & -1.1288 \\
\hline 9 & 31 & 2034 & 2077 & 2036.16 & 1.9838 \\
\hline 10 & 34 & 2113 & 2159 & 2110.86 & 2.2151 \\
\hline 11 & 36 & 2136 & 2145 & 2120.70 & 1.1388 \\
\hline 12 & 39 & 2133 & 2165 & 2120.77 & 2.0207 \\
\hline 13 & 40 & 2036 & 2088 & 2046.63 & 1.9617 \\
\hline 14 & 42 & 2105 & 2141 & 2098.19 & 2.0209 \\
\hline 15 & 43 & 2122 & 2187 & 2104.67 & 3.7482 \\
\hline 16 & 43 & 2090 & 2160 & 2070.70 & 4.1324 \\
\hline 17 & 43 & 2030 & 2062 & 2011.70 & 2.4619 \\
\hline 18 & 42 & 1971 & 2043 & 1981.00 & 3.0503 \\
\hline 19 & 39 & 1957 & 2010 & 1986.13 & 1.1747 \\
\hline 20 & 36 & 2014 & 2105 & 2009.46 & 4.5592 \\
\hline 21 & 34 & 2025 & 2072 & 2013.67 & 2.8235 \\
\hline 22 & 33 & 1989 & 2102 & 2008.34 & 4.4401 \\
\hline 23 & 33 & 2024 & 2093 & 2014.83 & 3.7509 \\
\hline 24 & 31 & 2050 & 2168 & 2023.16 & 6.6855 \\
\hline
\end{tabular}

\section{RESULTS}

The results obtained from the fuzzy logic are compared with the conventional method as well as artificial neural network of short term load forecasting and the error is in the range of $1.884780 \%$ to +2.695659 for fuzzy logic and in the range of 3.7580145 to +2.552835 . The load curve is plotted which is the comparison between the actual load, fuzzy forecasted load and artificial neural network forecasted load. Figure (Fig -8) and figure (Fig -9) shows the load curve plot for 8th May 2013 and 9th May 2013 respectively. From the curve it is observed that fuzzy forecasted load curve is very close to the actual load curve.

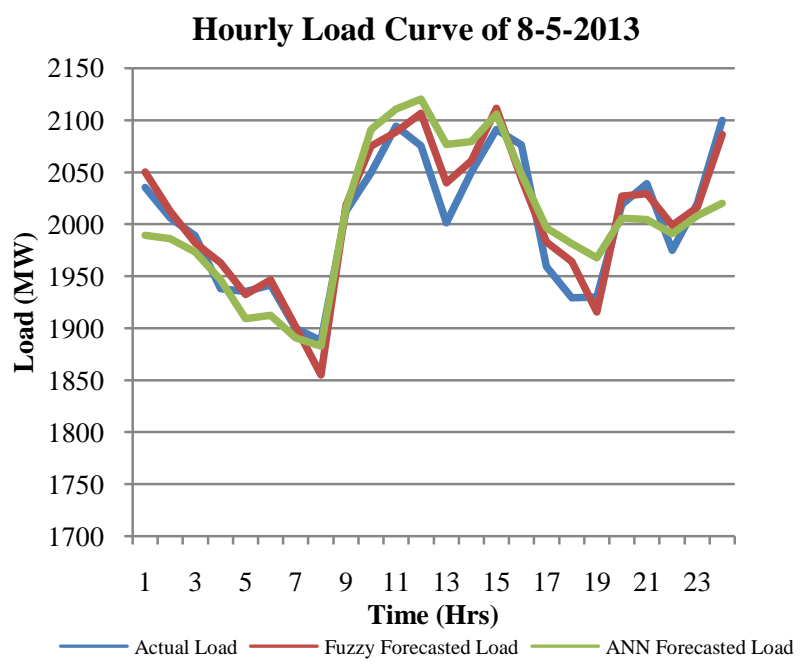

Fig -8: Hourly load curve of 8th May 2013

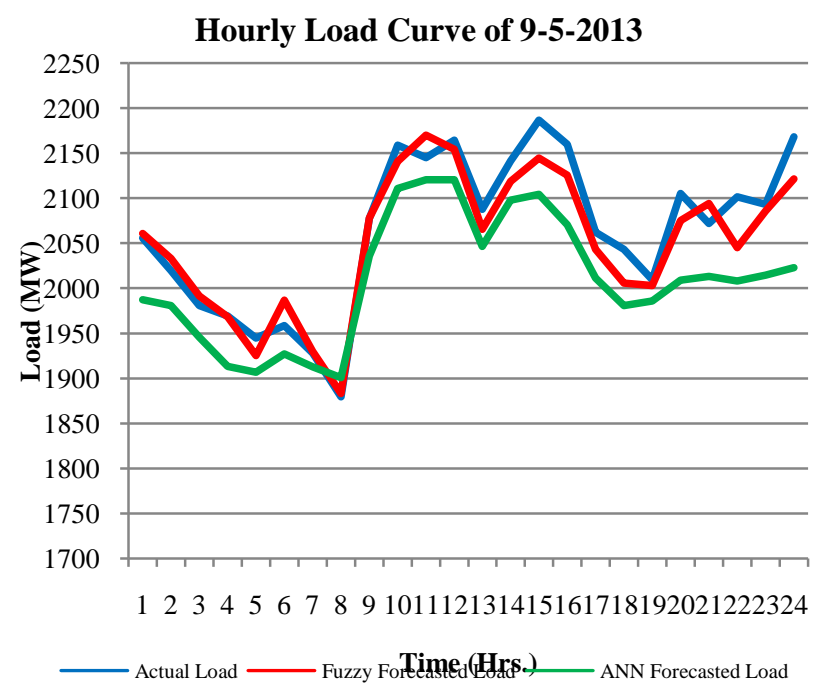

Fig -9: Hourly load curve of 9th May 2013

\section{CONCLUSIONS}

In this paper fuzzy and ANN methodology for short term load forecasting is discussed. It is concluded that using time, temperature and similar previous day load as the inputs and by formulating rule base of fuzzy logic using available data, load forecasting is done with an error margin of $-1.884780 \%$ to $+2.695659 \%$, whereas in case of artificial neural network the error margin is of -3.758015 to +2.552835 . It is seen that fuzzy logic approach gives better results as compared to 
artificial neural network. Moreover, it is also concluded that fuzzy logic approach is very easy for the forecaster to understand as it works on simple "IF-THEN" statements.

\section{ACKNOWLEDGEMENTS}

I extend my thank to Mr. Pareshkumar J. Bhatt, Executive Engineer in Operation and Management, Rural Division Office, Ankleshwar, for his support in giving through knowledge in load forecasting; also I like to thank Mr. Kunvarji M. Vasava, Junior Engineer in Demand Side Management, Area Load Dispatch Centre, DGVCL, Jambuva, for his help and support.

\section{REFERENCES}

[1]. Engr. Badar Ul Islam, Head of Department Computer Science \& Engineering, NFC-Institute of Engineering \& Fertilizer Research, Faisalabad - Pakistan, "Comparison of Conventional and Modern Load Forecasting Techniques Based on Artificial Intelligence and Expert Systems", IJCSI International Journal of Computer Science Issues, Vol. 8, Issue 5, No 3, September 2011.

[2]. Rustum Mamlook, Middle East University for Graduate Studies, Faculty of Information Technology, Amman 11942, Jordan, Omar Badran, Emad Abdulhadi, Al-Balqa Applied University, Faculty of Engineering Technology, Amman, Jordan, "A fuzzy inference model for short-term load forecasting", Energy Policy37(2009)1239-1248, January 2009.

[3]. Sandeep Sachdeva, Haryana Engineering College, Jagadhri, District Yamuna Nagar, Haryana, INDIA and Chander Mohan Verma, Haryana Power Generation Corporation Ltd., Yamuna Nagar, Haryana, India, "Load Forecasting using Fuzzy Methods", IEEE Transaction, 2008.

[4]. S. Chenthur Pandian, K. Duraiswamyaa, Electrical and Electronics Engg., K.S. Rangasamy College of Technology, Tiruchengode 637209, Tamil Nadu, India, C. Christober Asir Rajan, N. Kanagaraj, Department of Electrical and Electronics Engineering, Pondicherry Engineering College, Pondicherry, India, "Fuzzy approach for short term load forecasting", Electric Power Systems Research 76 (2006) 541-548, November 2005.

[5]. Hesham K. Alfares and Mohammad Nazeeruddin, Systems Engineering Department, King Fahd University of Petroleum \& Minerals, Dhahran 31261 , Saudi Arabia, "Electric load forecasting: literature survey and classification of methods", International Journal of Systems Science, 2002, volume 33, number 1, pages 23-34.

[6]. D K Ranaweera, N F Hubeleand and G G Karady, Arizona State University, Tempe, Arizona, USA, "Fuzzy logic for short term load forecasting", Electrical Power \& Energy Systems, Vol. 18 No. 4, pp. 215-222, 1996.

[7]. Abhisek Ukil, Intelligent Systems and Signal Processing in Power Engineering, Springer-Verlag Berlin Heidelberg, 2007, pp. 5-159.
[8]. D P Kothari \& J P Nagrath, Mordern Power System Analysis, 3rd Edn., Tata McGraw Hill Education private Limited, New Delhi, 2009, pp. 575-589.

[9]. "Collection of load data", Area Load Dispatch Centre, DGVCL, Jambuva, Vadodara.

\section{BIOGRAPHIES}

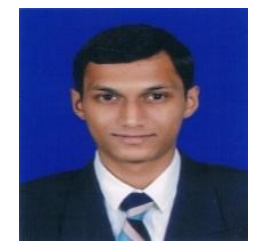

Patel Parth Manoj born on October 15, 1990 in Surat, Gujarat, India. He completed his B.E. in Electrical Engineering from C.K. Pithawalla College of Engg. and Tech. from Gujarat Technological University in 2012. He is currently pursuing his Post Graduation in Electrical Engineering from Parul Institute of Engg. and Tech., Vadodara. His field of interest is Power Systems, Artificial Intelligence.

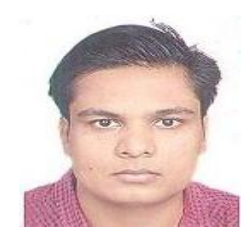

Ashish Pravinchandra Shah born on May 15, 1988 in Banswara, Rajasthan, India. He completed his B.E. in Electrical Engineering from Gujarat University in 2009. He had his Post Graduation in Electrical Engineering from Nirma University, Ahmedabad in July 2013. He is currently working as Assistant Professor in Electrical Engineering Department, Parul Institute of Engg. and Tech. He had published three papers till date. His field of interest is Smart Grid, HVAC and HVDC, Renewable Technology, Artificial Intelligence. 